\title{
Modern curriculum development for Informatics (Computing Science)
}

\author{
Tom J. van Weert and Fred Mulder \\ Expert Center for Educational Technology CETIS, Hogeschool van Utrecht, P.O. Box 85029, \\ 3508 AA Utrecht, The Netherlands, t.vweert@cetis.hvu.nl
}

Executive Board, Open University of the Netherlands, P.O. Box 2960, 6401 DL Heerlen, The Netherlands,fred.mulder@ou.nl

Key words: Computer Science, Curriculum Policies, Higher Education, Responsibility, Society

Abstract: Modern curriculum development should fulfil specific requirements that reflect developments in society. A proposed set of requirements is compared against two recent curriculum development initiatives in the area of informatics (computing science). The two initiatives are the IEEE-CS/ACM Computing Curriculum 2001 (Joint Taskforce 2001) and the IFIP/UNESCO Informatics Curriculum Framework 2000 (ICF-2000) (Mulder and van Weert 2001). Detailed comparison showed that the principles used in these two initiatives cover the proposed requirements, although not one-to-one and with different emphasis. A difference in approach between the two curriculum initiatives, concerning the linking of societal needs and student competence development, is illustrated by explaining ICF-2000 Professional Categories and Graduate Profiles.

\section{CURRICULUM DEVELOPMENT TRADITION}

There is a long tradition in curriculum development in higher education. A common approach is to make a list of topics from the discipline involved, ordered by topic area and increasing complexity. Didactic guidelines are then added to specify how these topics should be taught to students. The

The original version of this chapter was revised: The copyright line was incorrect. This has been corrected. The Erratum to this chapter is available at DOI: 10.1007/978-0-387-35663-1_34 
curriculum effort is driven by the content of the discipline and many curriculum discussions focus on how important specific topics are to the curriculum. Clearly topic stakeholders play an important role in these discussions and may bias the resultant decisions.

Education exists to serve society: to supply society with capable graduates for its workforce and to assure common values. Mass education for industrial society did exactly that when it started, through its overt and hidden curriculum. However, mass education today has become a complex system with high inertia. It is more involved with its own, autonomous problems than with what is happening in society. Consequently many curriculum developers take more account of the needs of the educational system and its hierarchy than of the needs of society.

\section{DEVELOPMENTS IN SOCIETY}

We live in societies that are affected by the trend of globalisation, where English is becoming the "world Esperanto" and the job market increasingly global. Professionals may therefore be active in several different cultures and business settings.

Our societies exhibit a rapid rate of change and innovation is essential. Knowledge has become a common commodity; access to knowledge and reproduction of that knowledge is becoming easier and easier. On the other hand the development of knowledge has become a common activity of the new professional. "Time to market" is critical and therefore there is a need to develop new knowledge that is applied almost immediately in innovative situations. "Life Long Learning" is nothing special - it's now a characteristic of professional life.

Modern society experiences many problems that need a multidisciplinary team approach and professionals work in such teams in which hierarchy is not important and respect is earned by achievement.

Clearly modern society is facing new types of problems. Their resolution requires a new type of professional who should be able to:

- Deal with these new types of problems in innovative ways.

- Create the new knowledge that must be applied to solve these problems.

- Work in multi-disciplinary teams and in an international context. 


\section{REQUIREMENTS FOR CURRICULUM DEVELOPMENT}

The developments outlined in the preceding section have implications for higher education and curriculum development.

Modern society wants to know that what it gets is what it needs. Therefore a first, overall requirement for curriculum development is accountability. Curriculum developers have to answer the following questions:

- Why should the curriculum be developed?

- For whom is the curriculum primarily developed?

- What will the curriculum address, and why?

- How will the curriculum be realised in an effective way?

These key questions can be refined into requirements and are listed in Table 1.

Table 1. Requirements for modern curriculum development

\begin{tabular}{ll}
\hline Key Questions & Curriculum Requirements \\
\hline Why should the curriculum be developed? & 0 - Meet society's need to deal with new \\
& types of problems \\
& 1 - Meet society's need for professionals \\
& 2 - Meet need of individuals for personal \\
development \\
For whom is the curriculum primarily & 3 - Students who develop competencies \\
developed? & a. to build up a broad knowledge base \\
& b. to apply this base in a professional context \\
& c. to move along a path of personal growth \\
What should the curriculum address? & 4 - Application of knowledge \\
& 5 - Core disciplinary competencies \\
& 6 - Professional competencies \\
& 7 - Personal growth achievements \\
& 8 - Interdisciplinary characteristics \\
& 9 - Globalisation effects \\
& 10 - Through a pedagogic and didactic \\
How should the curriculum be realised? & approach \\
& 11 - In an effective and efficient process \\
12 - With implementation flexibility \\
13 - Combining sustainability and frequent \\
\hline
\end{tabular}




\subsection{Informatics curriculum development in practice}

At the 2001 International Federation for Information Processing (IFIP) World Conference on Computers in Education (WCCE2001), in Copenhagen, two curriculum documents were discussed.

- Computing Curricula 2001 (CC2001), Steelman Draft (August 1, 2001), produced by the Joint Taskforce on Computing Curricula of the IEEE Computer Society (IEEE-CS) and the Association for Computing Machinery (ACM).

- Informatics Curriculum Framework 2000 (ICF-2000), produced by Technical Committee 3 of IFIP on behalf of UNESCO.

Both curriculum documents are based on principles that can be interpreted as requirements for curriculum development.

\subsection{Principles used to develop CC2001 (IEEE-CS/ACM)}

The CC2001 Taskforce articulated the following principles (Joint Taskforce 2001)

1. Computing is a broad field that extends well beyond the boundaries of computer science.

2. Computer science draws its foundations from a wide variety of disciplines.

3. The rapid evolution of computer science requires an ongoing review of the corresponding curriculum.

4. Development of a computer science curriculum must be sensitive to changes in technology, new developments in pedagogy, and the importance of lifelong learning.

5. CC2001 must go beyond knowledge units to offer significant guidance in individual course design.

6. CC2001 should seek to identify the fundamental skills and knowledge that all computing students must possess.

7. The required body of knowledge must be made as small as possible.

8. CC2001 must strive to be international in scope.

9. The development of CC2001 must be broadly based.

10. CC2001 must include professional practice as an integral component of the undergraduate curriculum.

11. CC2001 must include discussions of strategies and tactics for implementation along with high-level recommendations. 


\subsection{Principles used to develop ICF-2000 (IFIP/UNESCO)}

These principles were derived from the introduction of ICF-2000 (Mulder and van Weert 2000; van Weert 2000; Mulder and van Weert 2001)

1.The curriculum framework has an international scope and is developed for flexible and efficient implementation in different countries and different cultural and economic environments.

2. ICF-2000 takes a generic and inclusive view on the field of informatics.

3. ICF-2000 offers a global specification of necessary professional categories and profiles in terms of student competencies.

4. Professional categories are to be identified for which the curriculum should provide education; these categories should take account of other disciplines.

5. Graduate profiles are to be identified to cater for the educational needs of the professional categories in an efficient way; these profiles should take account of other disciplines.

6. Graduate profiles should build one upon the other allowing for efficient and flexible implementation in different educational environments.

7. Implementation of the curriculum should be possible within several resource situations.

8. Core informatics themes are to be identified and addressed in curriculum units; these themes should include personal and inter-personal skills.

9. Levels of competence should be specified for graduate profiles and curriculum units.

10. Learning approaches are to be specified for curriculum units.

11. International curriculum sources should be used for building an actual curriculum assuring that the curriculum is "state of the art", easy to maintain and allows for use of existing learning materials in many languages.

\subsection{Requirements analysis}

Comparison of the list of requirements shown in Table 1 with the principles used in the construction of the curriculum documents produces the result shown in Table 2. The classification is not straightforward and is open to debate. Also the authors are biased through their involvement in the development of ICF-2000. However, Table 2 illustrates that the requirements identified in the beginning of this paper are generally satisfied by the practical curriculum development for informatics (computing science). 
Table 2. Coverage of requirements in practice

\begin{tabular}{lll}
\hline Requirements & $\begin{array}{l}\text { CC2001 } \\
\text { Principles }\end{array}$ & $\begin{array}{l}\text { ICF-2000 } \\
\text { Principles }\end{array}$ \\
\hline Overall accountability & Yes & Yes \\
& & \\
Why should the curriculum be developed? & 4 (re. new & $1,3,4$ \\
Meet the need of society to deal with new types of & technology) & \\
problems & 9 & 3,45 \\
Meet the need of society for professionals & 4 & $3,5,8$ \\
Meet the need of individuals for personal development & & \\
For whom is the curriculum primarily developed? & & 3,9 \\
Students who develop competencies & 1,2 & 2,3 \\
a. to build up a broad knowledge base & 10 & 4 \\
b. to apply this base in a professional context & & 3,9 \\
c. to move along a path of personal growth & 10 & 3 \\
What should the curriculum address? & 6,7 & 8,9 \\
Application of knowledge & 10 & $3,4,5$ \\
Core disciplinary competencies & & 8,9 \\
Professional competencies & 2 & 4,5 \\
Personal growth achievements & 8 & 1 \\
Inter-disciplinary characteristics & & \\
Globalisation effects & 4,5 & 10 \\
How should the curriculum be realised? & 5,7 & $1,5,6$ \\
Through a pedagogic and didactic approach & 11 & $1,6,7$ \\
In an effective and efficient process & 3,4 & 11 \\
With implementation flexibility & & \\
Combining sustainability and frequent updating & &
\end{tabular}

When the two lists of curriculum principles are compared, it can be noted that the principles of $\mathrm{CC} 2001$ are of a more general nature than the principles of ICF-2000. In the last case reference is made in Principles 3, 4 and 5 to the curriculum elements 'professional categories' and 'graduate profiles'. In fact the principles of ICF-2000 in part already explain how the actual curriculum development will meet some of the principles.

The comparison also shows that in Principle 3 of ICF-2000 student competencies are introduced as an educational aim (to be realised in graduate profiles and curriculum units) while in CC2001 student competencies are only referred to in Principle 10. The combination of observations offers an explanation for the appearance of ICF-2000 Principles 3,4 and 5 in several places in Table 2 . 


\section{COMPARISON OF CC2001 AND ICF-2000}

Comparison of the principles of the curriculum documents using the requirement framework in Table 2 shows that, in the case of ICF-2000, more attention appears to be given to the following requirements:

1. Meet the need of society for professionals

2. Meet the need of individuals for personal development

3. Students who develop competencies ... (c) to move along a path of personal growth

7. Personal growth achievements

8. Inter-disciplinarity characteristics

A more in-depth study of the documents shows that there indeed is a difference. ICF-2000 (Mulder and van Weert 2000 - Sections 4 and 5) tries to specifically link - societal needs, to categories of professionals, to competence development of students - before moving to a curriculum description (Mulder and van Weert 2000 - Sections 9 to 12).

Such a link is more diffuse in CC2001 (Joint Taskforce 2001) which centres on a topical curriculum description in Chapter 5 and gives a "variety of approaches to cover core units in the body of knowledge" in Chapter 7 (Introductory courses) and Chapter 8 (Intermediate courses). It only refers to Professional Practice and Characteristics of Computer Science graduates in Chapters 10 and 11. In view of this difference in approach the specific link between societal needs and competence development of students merits separate attention.

\subsection{Linking society needs and student competence development}

ICF-2000 deals with university and higher professional education. It gives a specification of categories of professionals in section 4 . What informatics competencies do professionals, who have been educated in higher education and are starting their professional career, need? This knowledge should fit the role these professionals will fulfil in economic life, in an effective and efficient way.

\subsection{Three main categories}

Looking at the role professionals play in the economic process three categories of professionals can be identified, acting or interacting with Informatics (I) in a broad sense: 


\section{A I-users:}

Non-I-professionals using ready made I-technology or I-applications in their work, for example non-informatics professionals using digital communication systems or text processors. Many professionals in highly developed economies are I-users.

\section{B I-appliers:}

Non-I-professionals applying I-knowledge and I-skills in areas different from informatics, for example non-informatics professionals in the economic field who use I-applications to model economic situations.

\section{CI-workers:}

I-professionals working in the field of informatics like the system engineer who develops I-applications or I-technology (note that the field of informatics is broad with diffuse boundaries with other disciplines).

It is important to note that I-appliers and I-workers generally will also be I-users, while I-workers may or may not be I-appliers.

\subsection{Categories of professionals}

Within the main categories eight subcategories are identified.

\section{A1 Instrumental I-users}

They use computer technology or software packages in their work. Examples can be found in word processing, using databases, making spreadsheets, preparing presentations, graphical drawing, communicating by e-mail, retrieving information through the Internet and videoconferencing.

\section{B1 Conceptual I-appliers}

Conceptual I-appliers apply specific knowledge from the informatics domain or typical informatics skills in their own area that is increasingly infused by informatics. Examples include teachers who design computer supported education, chemists doing molecular modelling, computer artists, the media specialists applying internet technology and economists introducing electronic commerce.

\section{B2 Interfacing I-appliers}

These professionals combine knowledge and skills from their own area or profession with informatics knowledge and skills, in an interfacing role linked to I-professionals. Examples are the business consultant advising on the development of computer based information systems, the mechanical engineer participating in industrial automation projects, the sociologist supporting the introduction of large scale work computerisation, the ethicist advising on privacy matters and the lawyer collaborating on the formulation of software contracts. 


\section{B3 Researching I-appliers}

Researching I-appliers combine knowledge and skills from their own research areas with informatics knowledge and skills in research efforts that connect and integrate informatics with other disciplines. In general interdisciplinary research projects show fruitful collaborations with informatics researchers (C3) and are designed to open up new horizons. Examples can be found in research on distance learning, human-computer interaction, cognition, computational science, telematics \& multimedia, linguistics, information science, knowledge technology and logistics.

\section{B4 Directing I-appliers}

Directing I-appliers are well equipped and skilled through their general understanding and broad overview of informatics, to play a policymaking, supervisory or managerial role in the areas of I-technology and Iapplications. The project manager running a project in which new Itechnologies are introduced into an organisation or in which a tailored Iapplication is being developed is one example. Others include the information (policy) manager supervising an organisation's information processing and the communication (policy) manager responsible for creating, updating and exploiting an Internet site of substantial volume.

\section{C1 Operational I-workers}

They have a thorough understanding of and well-developed skills in informatics as a broad discipline, more specifically in the area of exploitation, control and maintenance of available I-technology and Iapplications. Clearly this category contains a large portion of lower level Iprofessionals, for example computer operators, network operators, application administrators, database administrators and helpdesk employees. University-level I-professionals will be required in directing, supervising and managing roles in this area (note a possible overlap with B4).

\section{C2 Engineering I-workers}

Engineering I-workers have a thorough understanding of and welldeveloped skills in informatics as a broad discipline, more specifically in the area of analysis, design and implementation of I-systems. Examples include the information systems analyst, the software engineer, the knowledge engineer, the scientific programmer, the database developer and the integrated circuit designer.

\section{C3 Researching I-workers}

Researching I-workers have a thorough understanding of and welldeveloped skills in informatics as a broad discipline, more specifically in research. They are supposed to further develop the I-discipline and its concepts, both on its own and in relation with other disciplines, in the latter case collaborating with researchers from category B3. 


\section{GRADUATE PROFILES}

To allow effective education of all eight professional categories ICF2000 identifies the following four graduate profiles (Mulder and van Weert 2000 - Section 5) that build upon each other.

\section{Professional Orientation \\ ICF-2000 \\ Category}

\section{BIP}

A1

Awareness

Basic Instrumental I-Profile

\section{BCP}

$$
\text { [Section 9] }
$$

Basic Conceptual I-Profile

\section{MIP}

MInor I-Profile

B1

Application

[Section 10]

4. MAP

MAjor I-Profile

B2, B3, B4 Design

[Section 11]

Modelling

C1, C2, C3 Conceptualisation

[Section 12]

Abstraction

\subsection{Profile fingerprint and orientation}

The professional categories grouped in a graduate profile have characteristics that reflect differences between the graduate profiles. These differences are related to:

- The coverage of informatics core curriculum themes which 'fingerprints' the graduate profile for a specific category of professionals.

- The orientation in terms of goals and competencies to be reached.

Core curriculum themes

Twelve I-curriculum themes are identified that globally offer a complete coverage of the informatics field. The themes were developed at an IFIP Working Conference (Mulder and van Weert 1998) and essentially set the curriculum framework which defines the core of informatics education. These also allow the relationship of informatics with other disciplines to be clarified.

1. Representation of information;

2. Formalism in information processing;

3. Information modelling;

4. Algorithmics;

5. System design; 
6.Software development;

7.Potentials/limitations of computing and related technologies;

8.Computer systems and architectures;

9.Computer-based communication;

10. Social and ethical implications;

11. Personal and interpersonal skills;

12. Broader perspectives/context (links to other disciplines).

The coverage of the themes in a graduate profile constitutes a 'fingerprint' fitting specific categories of professionals.

\section{Orientations}

Each graduate profile has a dominant orientation in term of goals with competencies fitting specific categories of professionals. There are four orientations:

AW AWareness (know or use)

Aimed at developing basic knowledge and skills that allow students to acquire basic literacy with respect to informatics in general and to perform standard operations using computer technology or software packages;

AP APplication

Aimed at developing basic conceptual understanding of informatics and of some more advanced informatics skills which allow students to apply basic informatics to other disciplines or areas;

DM Design and Modelling

Aimed at developing a general understanding and broad overview of informatics, especially with respect to the modelling and design of informatics applications;

\section{CA Conceptualisation and Abstraction}

Aimed at developing a thorough understanding of, and well-developed skills in, informatics as a broad discipline, the essence being to further develop the capability of students to abstract and to conceptualise.

\section{REFERENCES}

The Joint Taskforce on Computing Curricula (2001) Computing Curricula 2001. Steelman Draft (August 1, 2001. IEEE Computer Society \& Association for Computing Machinery, IEEE CS/ACM.

[http://www.acm.org]

Mulder, F. and van Weert, T. J. (2000) Informatics Curriculum Framework 2000 for higher education [ICF-2000], UNESCO, Paris.

[http://www.ifip.or.at/pdf/ICF2001.pdf]

van Weert, T. J. (2000) Guidelines for Authors, Informatics Curriculum Framework 2000 for higher education [ICF-2000], UNESCO, Paris. 
Mulder, F. and van Weert, T. J. (2001) IFIP/UNESCO's Informatics Curriculum Framework 2000 for Higher Education, SIGCSE Bulletin, Association for Computing Machinery (ACM), Vol 33, No4, December. pp. 75-83.

Mulder, F. and van Weert, T.J. (eds) (1998) Informatics in higher education: Views on informatics and noninformatics curricula, Proceedings of the IFIP/WG3.2 Working Conference on Informatics (computer science) as a discipline and in other disciplines: what is in common? Chapman \& Hall, London. 